\title{
Should you screen all your sleep apnea patients for thyroid disease?
}

\author{
Aaron B. Holley
}

Received: 12 March 2014 /Revised: 11 April 2014 / Accepted: 30 April 2014 / Published online: 20 May 2014

(C) Springer-Verlag (outside the USA) 2014

In this issue of Sleep and Breathing, Takeuchi et al. provide data on thyroid function testing in patients referred for suspicion of having obstructive sleep apnea (OSA) [1]. The authors cite the controversy over routine thyroid screening for patients diagnosed with OSA as the rationale for their investigation. Among 156 consecutive subjects, they found three (1.6\%) met laboratory criteria for clinical and one $(0.6 \%)$ for subclinical hypothyroidism. Although prevalence of thyroid disease varies by age, gender, dietary iodine intake, and other factors, the numbers reported by the authors are at or below what might be expected for the general population [2].

I believe their study highlights two issues that often arise when defining the relationship between OSA and comorbid diseases. The first relates to the prevalence of OSA. To estimate prevalence in the general population, most authors cite the Wisconsin Sleep Cohort data and report $4 \%$ of males and $2 \%$ of females between the ages of 30 and 60 will have OSA syndrome (an apnea-hypopnea index (AHI) $\geq 5$ plus symptoms). The Wisconsin Sleep Cohort numbers for AHI $\geq 5$ were 24 and $9 \%$ for men and women, respectively, and the investigators used a thermocouple without a pressure transducer (PTAF) to score respiratory events and required an oxygen saturation drop of $\geq 4 \%$ to score a hypopnea [3].

In 2012, the American Academy of Sleep Medicine (AASM) updated their guidelines for scoring respiratory events on polysomnography (PSG). They recommend scoring a hypopnea when there is $\mathrm{a} \geq 30 \%$ drop in the PTAF accompanied by a $3 \%$ desaturation $\mathrm{OR}$ an arousal. If these criteria were applied to the original Wisconsin Sleep Cohort, the number of patients with an $\mathrm{AHI} \geq 5$ would increase dramati-

A. B. Holley ( $\bowtie)$

Walter Reed National Military Medical Center, Bethesda, MD, USA

e-mail: aholley9@gmail.com cally [4]. Furthermore, regardless of the criteria used, the prevalence estimates for adults older than 65 tend to be considerably higher [5].

What does this have to do with OSA and thyroid disease? Suppose we take a group of patients with a given disease. Perhaps this disease is related to aging and associated with symptoms of fatigue, lethargy, and sleepiness. We order PSG on all these patients and find that $50 \%$ of them have an AHI $\geq 5$ according to AASM 2012 scoring criteria. Have we identified an important causal relationship or simply confirmed the fact that if you set your diagnostic criteria low enough without adjusting for age you will find a lot of OSA?

The second issue relates to OSA phenotype. While Takeuchi et al. found that thyroid levels were not related to AHI but TSH and FT3 were weakly associated with apnea duration. This fits with what we already know - hypothyroidism blunts the ventilatory response to hypoxia and hypercapnia [6]. The effect that such "blunting" will have on the AHI might vary by OSA phenotype. For patients with high loop gain and a tendency for ventilatory overshoot, such blunting may provide relative stability and a decrease in AHI [7, 8]. The impact that thyroid replacement has on sleep-related breathing abnormalities may therefore vary by phenotype. This could account for the absence of a correlation between thyroid level and overall AHI in their patients.

At our sleep center, we do not routinely draw thyroid levels on every patient diagnosed with OSA. Considering the data presented by Takeuchi et al. and the previously published literature that they reference, I see no reason to change this practice. It is not clear that hypothyroidism occurs at a higher frequency among patients with OSA. Given the modest and variable effects that minor thyroid level abnormalities have on respiratory function during sleep, it seems unlikely that thyroid replacement will be an important part of OSA treatment in most cases. 


\section{References}

1. Takeuchi S, Kitamura T, Ohbuchi T, Koizumi H, Takahashi R, Hohchi N, Suzuki H (2014) Relationship between sleep apnea and thyroid function. Sleep Breathing

2. Canaris G, Manowitz NR, Mayor G, Ridgway C (2000) The Colorado thyroid disease prevalence study. Arch Int Med 160: $526-534$

3. Young T, Palta M, Dempsey J, Skatrud J, Weber S, Badr S (1993) The occurrence of sleep-disordered breathing among middle-aged adults. N Engl J Med 328:1230-1235

4. Ruehland W, Rochford PD, O'Donoghue FJ, Pierce RJ, Singh P, Thorton AT (2009) The new AASM criteria for scoring hypopneas: impact on the apnea hypopnea index. Sleep 32:150157

5. Ancoli-Isreal S, Kripke DF, Klauber MR, Mason WJ, Kaplan O (1991) Sleep-disordered breathing in community-dwelling elderly. Sleep 14: 486-495

6. Zwillich C, Pierson DJ, Hofeldt FD, Lufkin EG, Weil JV (1975) Ventilatory control in myxedema and hypothyroidism. N Engl J Med 292:662-665

7. Eckert D, White DP, Jordan AS, Malhotra A, Wellman A (2013) Defining phenotypic causes of obstructive sleep apnea: identification of novel targets. Am J Respir Crit Care Med 188:996-1004

8. Younes M (2008) Role of respiratory control mechanisms in the pathogenesis of obstructive sleep disorders. J Appl Physiol 105: 1389-1405 